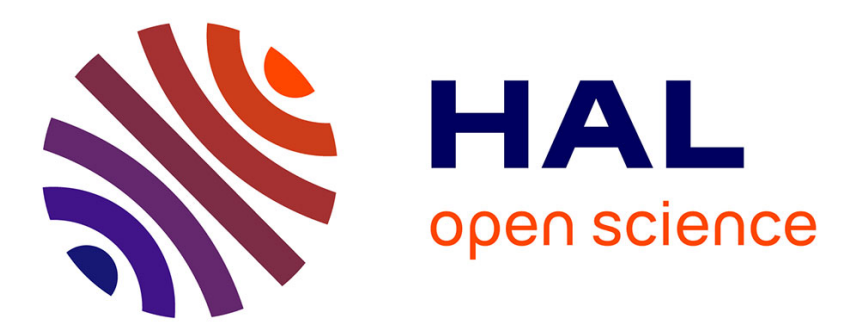

\title{
Light emitting diodes on silicon substrates: preliminary results
}

Alexandre Bondi, Weiming Guo, Laurent Pedesseau, Soline Richard, Hervé

Folliot, Charles Cornet, Christophe Labbé, Maud Gicquel-Guézo, Alain Le

Corre, Jacky Even, et al.

\section{To cite this version:}

Alexandre Bondi, Weiming Guo, Laurent Pedesseau, Soline Richard, Hervé Folliot, et al.. Light emitting diodes on silicon substrates: preliminary results. TNT (Trends in Nanotechnologies), Sep 2008, Oviedo, Spain. pp.2212-16, 10.1002/pssc.200881728 . hal-00491905

\section{HAL Id: hal-00491905 https://hal.science/hal-00491905}

Submitted on 14 Jun 2010

HAL is a multi-disciplinary open access archive for the deposit and dissemination of scientific research documents, whether they are published or not. The documents may come from teaching and research institutions in France or abroad, or from public or private research centers.
L'archive ouverte pluridisciplinaire HAL, est destinée au dépôt et à la diffusion de documents scientifiques de niveau recherche, publiés ou non, émanant des établissements d'enseignement et de recherche français ou étrangers, des laboratoires publics ou privés. 


\title{
LIGHT EMITTING DIODES ON SILICON SUBSTRATES: PRELIMINARY RESULTS
}

\author{
A. BONDI, W. GUO, L. PEDESSEAU, S. RICHARD, H. FOLLIOT, C. CORNET, C. LABBE, \\ M. GICQUEL, A. LE CORRE, J. EVEN, A. MOREAC*, S. LOUALICHE \\ CNRS UMR 6082 FOTON, INSA, 20 Avenue des Buttes de Coësmes, CS 14315, 35043 \\ RENNES, France \\ *I.P.R. UMR-CNRS n6251, Université Rennes1, Campus de Beaulieu - 35042 Rennes, France \\ Alexandre.Bondi@ens.insa-rennes.fr
}

Silicon is the most widely used semiconductor in microelectronics industry but it presents an indirect bandgap unable to produce photons efficiently. GaP is almost lattice matched to silicon but it also has an indirect bandgap which does not allow photon emission in the transparency region of silicon. We therefore propose to grow quantum dot (QD) or quantum well (QW) light-emitting diodes by molecular beam epitaxy to obtain direct band gaps on $\mathrm{GaP}$ grown onto $\mathrm{Si}$ (Fig. 1). The major challenge for a GaP-based diode (fig 1-a) is to process a good active zone. For the GaP/Si-based diode (fig 1-b), the interface quality between $\mathrm{GaP}$ and $\mathrm{Si}$ is thus very important. Finally, we theoretically consider the use of InAs QDs as emitters with the help of $\mathrm{Ab}$ initio calculations.

First, the active zone is made of QDs or QWs. To test the efficiency of this active zone, photoluminescence (PL) measurements have been performed. Figure 2.a shows the GaAsP / GaP QWs PL spectra variation with temperature. Luminescence appears up to $281 \mathrm{~K}$ (almost room temperature). This PL peak shift with temperature is in agreement with the gap variation determined by Varshni law (figure 2.b).

The second goal to achieve is the growth of $\mathrm{GaP}$ on $\mathrm{Si}$ [1]. To characterize the interface, Raman spectroscopy was performed to obtain a strong evidence for the determination of the bonding nature of the cristal (Ga-Si or P-Si, ...). The first Raman Spectra (fig. 3) show Si and $\mathrm{GaP}$ characteristic peaks. A mapping of a GaP/Si pseudo-substrate is performed.

We have compared the band line-ups of InAs/GaP thanks to the classical calculations [2] with $\mathrm{Ab}$ initio method (fig.4). We consider InAs and GaP bulk crystals with the Local Density Approximation (LDA) [3] as pseudopotential plus GW correction using the many-body perturbation theory included in ABINIT package [4]. The $d$ electrons effect has been taken into account because they play an important role to describe the correct behaviour of these semiconductors. We do not include spin-orbit (SO) splitting in both calculations. There is a good agreement between both methods. The same study will be done for InP/GaP.

We have observed GaAsP/GaP QW photoluminescence up to room temperature. This kind of active zone is promising for light emitters integration onto $\mathrm{Si}$ substrate. GaP growth onto $\mathrm{Si}$ substrate has successfully been achieved and characterized by Raman scattering. Future works will be conducted to insert these active zones (QWs or QDs) into a diode.

\section{References:}

[1] V. K. Dixita1, Tapas Gangulia, T. K. Sharmaa, S. D. Singha, Ravi Kumara, S. Porwala, Pragya Tiwaric, Alka Ingaleb, and S. M. Oak, "Effect of two step growth process on structural, optical and electrical properties of MOVPE grown GaP/Si”, India, 2008. 
[2] Chuang S L "Physics of optoelectronic devices. Wiley Series in pure and Applied Optics.” Joseph W. Goodman, Series Editor, 1995.

[3] Troullier N and Martins J L 1991 Phys. Rev. B 43, 1993.

[4] Gonze X, Beuken J M, Caracas R, Detraux F, Fuchs M, Rignanese G M, Sindic L, Verstraete, M, Zerah G, Jollet F, Torrent M, Roy A, Mikami M, Ghosez Ph, Raty J Y, and Allan D C Comput. Mater. Sci. 25 478, 2002.

Figures:

a)

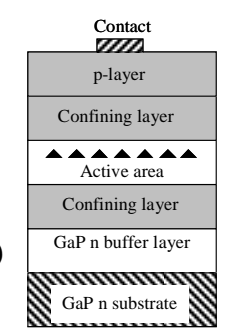

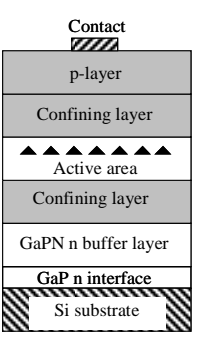

b)

Fig. 1: (a), structure of the future DEL with QDs or QWs on GaP substrate. (b), structure of the DEL with QDs or QWs on GaP deposited on silicon substrate.
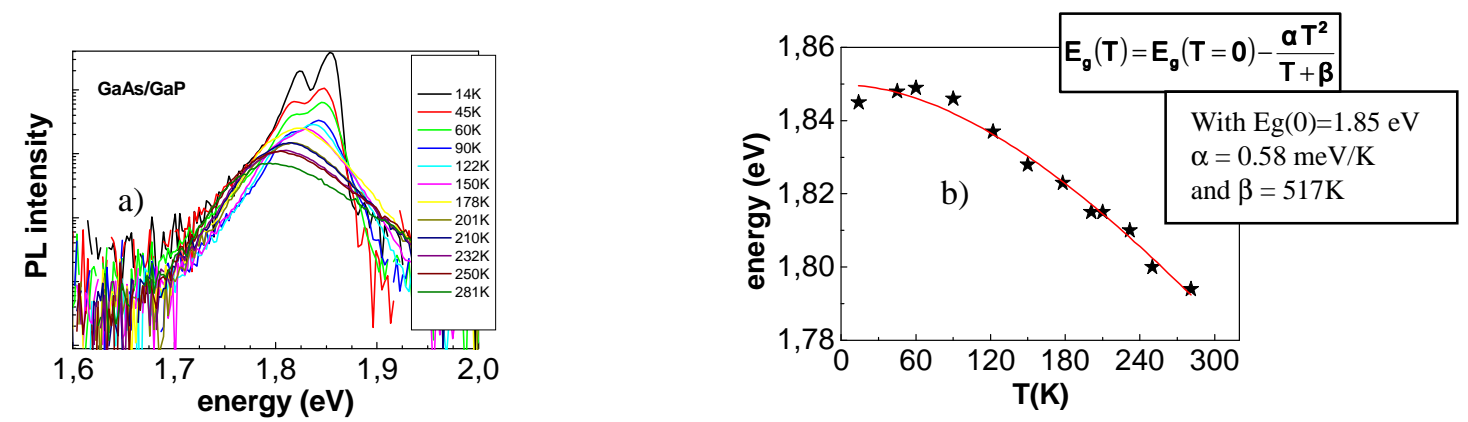

Fig. 2: (a), PL spectra of $\mathrm{GaAsP} / \mathrm{GaP}$ for several temperatures. (b), experimental datas following Varshni Law variation.

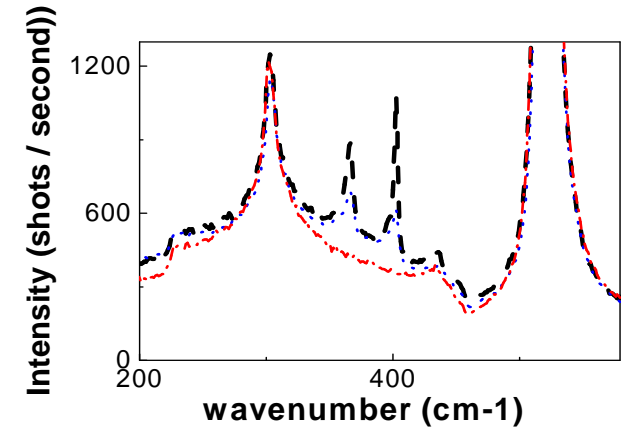

Fig. 3: Raman spectra performed on HR800 system (ONIS, University Rennes1). Dash dots indicate silicon Raman spectrum; Dashes, GaP on silicon Raman spectrum; Dots, an intermediate zone.
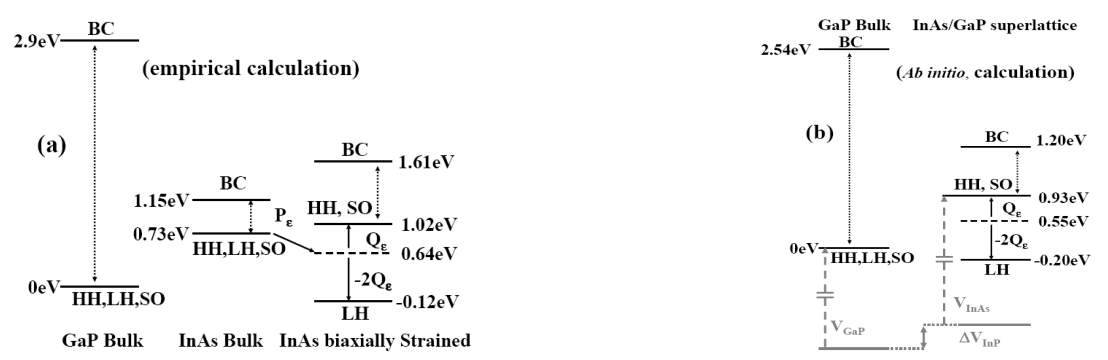

Fig. 4: Band line-ups at $\Gamma$ point calculated without $\mathrm{SO}$ coupling for both the classical empirical method (a) and Ab initio calculation (b). 